\title{
The impact of volatile compounds released by paper on cellulose degradation in ambient hygrothermal conditions
}

\author{
J. Tétreault ${ }^{\mathrm{a}, *}$, A.-L. Dupont ${ }^{\mathrm{b}}$, P. Bégin ${ }^{\mathrm{a}}$, S. Paris ${ }^{\mathrm{b}}$ \\ ${ }^{a}$ Canadian Conservation Institute, Department of Canadian Heritage, 1030 Innes Road, Ottawa, Ontario, Canada K1A 0M5 \\ ${ }^{\mathrm{b}}$ Centre de Recherche sur la Conservation des Collections, Muséum National d'Histoire Naturelle, CNRS USR 3224,36 rue Geoffroy-Saint-Hilaire, 75005 \\ Paris, France
}

\section{A R T I C L E I N F O}

\section{Article history:}

Received 5 November 2012

Received in revised form 19 April 2013

Accepted 17 May 2013

Available online 28 May 2013

\section{Keywords:}

Degree of polymerization

Formaldehyde

Formic acid

Hydrogen peroxide

Oxidation

VOC

\begin{abstract}
A B S T R A C T
The reactivity towards cellulose of various volatile compounds commonly released by paper was studied. Sheets of Whatman No. 1 (W1) and No. 40 (W40) were exposed to various concentrations of these compounds in vapour phase ranging from 20 to $80 \mathrm{ppm}$ in closed vessels for 52 days in controlled ambient conditions, after which they were hygrothermally aged. The measured properties of the paper were copper number, degree of polymerization, zero-span breaking length, $\mathrm{pH}$ and yellowness index. The results showed that hydrogen peroxide was the most aggressive among the volatile compounds tested as it severely degraded $\mathrm{W} 1$ cellulose. The exposure of $\mathrm{W} 1$ to formic acid led to significant degradation, designating this volatile organic compound (VOC) as the most reactive toward cellulose among the carboxyl and carbonyl functionalized VOCs tested. On the other hand, acetic acid was found comparatively less reactive. Nitrogen oxides, which were produced up to $3 \mathrm{ppm}$ from a side-reaction of the carboxylic acids with the magnesium nitrate used to control the relative humidity in the closed vessels, appeared to contribute significantly to the degradation despite their low concentration. Antagonistic effects were evidenced in binary vapour mixtures where the presence of aldehydes (formaldehyde and acetaldehyde) counteracted substantially the degradation induced by the most reactive compounds. It was also shown that acetaldehyde, hexanal and furfural in individual exposures had little to no reactivity. Upon exposure to formaldehyde, the rate of glycosidic bond cleavage of cellulose induced by the ageing of W1 was significantly reduced.
\end{abstract}

(c) 2013 Elsevier Ltd. All rights reserved.

\section{Introduction}

Notwithstanding recent developments, the research field of indoor air quality in heritage buildings is still in its infancy. Martin and Blades were among the first to report on the measurement of levels of volatile organic compounds (VOCs) inside museums in 1994 [1]. In 2003, an extensive review of the pollutants found in heritage institutions was conducted by Tétreault [2]. The bulk of this emerging research has largely been geared towards identifying and quantifying the pollutants in indoor air. The past decade, in particular, has seen a growing interest on the issue of indoor generated pollutants in libraries and archives. Recent studies have been devoted mostly to the measurement of VOCs in storage rooms housing paper-based collections, with a focus on carboxylic acids and aldehydes [3-6]. Research has also been dedicated to analysing

\footnotetext{
* Corresponding author. Tel.: +1 613998 3721; fax: +1 6139984721.

E-mail addresses: jean.tetreault@pch.gc.ca (J. Tétreault), aldupont@mnhn.fr (A.-L. Dupont), paul.begin@pch.gc.ca (P. Bégin), sparis@mnhn.fr (S. Paris).
}

emissions from papers and books [7-18], as the main sources of VOCs in archival storage rooms are the paper-based items themselves. In view of the adverse contribution of off-gassing from paper collections to the indoor air quality, Ramalho et al. measured the emission rates of a selection of VOCs identified in various types of unaged and aged model papers and in naturally aged books [19].

To date, little is known on the potential damaging effect of the VOCs on cultural objects. Upon measuring the emission levels of acetic acid from typical archival cardboard storage boxes, Dupont and Tétreault [20] evaluated the deterioration of paper exposed to ppm levels of acid vapour, in terms of decrease in degree of polymerization of the cellulose. More recently, high temperature exposures to formic acid, 2-pentyl furan and $\mathrm{NO}_{\mathrm{x}}$ at ppm levels were shown to unfavourably affect the degree of polymerization of cellulose in papers, while the effects of acetic acid were found to be more modest, and those of hexanal, furfural and formaldehyde were negligible on most papers [21,22]. Organic compounds with a high oxidative power such as hydroperoxides, the initial products in free radical autocatalytic oxidation, have been identified in pure 
cellulose paper [23-25]. Their presence was identified as free hydroperoxides cleaved from the cellulose chain as well as hydroperoxide functionalized cellulose, and their adverse impacts on cellulose degradation were quantified [24,25]. Hydroperoxides are also known to cause discolouration of black and white photographic prints [26,27]. Using Russell-effect images, Strlič et al. [28] were able to demonstrate that high levels of hydrogen peroxide $\left(\mathrm{H}_{2} \mathrm{O}_{2}\right)$ were produced in aged papers containing iron-gall ink. Despite this new knowledge, there are still gaps concerning the effects of VOCs on paper and cellulose-based materials in typical indoor environmental conditions.

The present research aims to identify the volatile compounds that can induce or initiate deterioration in cellulose, and to simulate their long-term effects on the stability of paper using artificial ageing. Unlike other investigations, the exposures were carried out in ambient conditions in order to observe possible damage in real time, as well as to avoid initiating chemical processes that can take place at elevated temperatures. Hygrothermal ageing was performed after a desorption period of 10 days following the exposures.

Two pure cotton cellulose papers were used: Whatman No. 1 (W1), with a high molar mass, neutral $\mathrm{pH}$ and negligible initial oxidation level, and Whatman No. 40 (W40), a lower molar mass, pre-oxidized and more acidic paper. In 'Phase I' of the research, the papers were exposed to individual volatile compounds commonly released by paper. These were acetaldehyde, acetic acid, formaldehyde, formic acid, furfural, hexanal and hydrogen peroxide. However, real situations are complex as they bring simultaneously into play a number of volatile compounds, which are both released and absorbed by paper, depending on environmental and intrinsic parameters. For instance, during hygrothermal ageing, crosscontamination from paper or cellulose-based storage materials to neighbouring paper has been observed [29]. Air chemistry can also take place, and new volatile compounds can arise from reactions between different volatile compounds. Since it is not possible to test all conceivable combinations of volatile compounds, in 'Phase II' of the research, the synergistic and/or antagonistic effects of exposures to binary mixtures of volatile compounds were assessed in an attempt to model real exposure situations. These combinations included two compounds, which had been identified in Phase I as highly reactive and less reactive at ambient temperature, respectively. The impact of exposures where adventitious nitrogen oxides $\left(\mathrm{NO}_{\mathrm{x}}\right)$ were additionally present was also investigated.

Previous studies have evaluated the migration of VOCs internally generated in stacks of paper $[30,31]$ and the migration of outdoor pollutants such as sulphur dioxide through papers [32] and cardboard [33]. To simulate paper sheets in a closed book this research also examined the migration of volatile compounds through stacks of paper from the edges inward at ambient conditions.

\section{Experimental}

\subsection{Chemicals}

Acetaldehyde (99\%), formaldehyde (37\%), furfural (99\%) and hexanal (98\%) were purchased from Sigma-Aldrich. Acetic acid glacial, formic acid (88\%), magnesium nitrate hexahydrate and sodium chloride were from Fisher Scientific. Hydrogen peroxide (30\%) was obtained from J.T. Baker.

\subsection{Generation and measurement of specific vapour phase environments}

A three component system of volatile compound-water-salt was used. This system is based on the equilibrium of water vapour with a saturated salt mixture and the equilibrium of a volatile compound between its vapour and liquid phases. Magnesium nitrate hexahydrate $\left(\mathrm{Mg}\left(\mathrm{NO}_{3}\right)_{2} \cdot 6 \mathrm{H}_{2} \mathrm{O}\right)$ and sodium chloride $(\mathrm{NaCl})$ were used to generate a relative humidity $(\mathrm{RH})$ of $54 \%$ and $75 \%$ at ambient temperature, respectively [34]. Aqueous solutions (40 ml) of the volatile compounds at different concentrations were mixed with $100 \mathrm{~g}$ of salt and placed in airtight $9 \mathrm{~L}$ Pyrex desiccators (200 $\mathrm{mm}$ i.d.). The presence of volatile compounds does not modify the $\mathrm{RH}$ in the desiccators, as shown in previous research [35]. Since hexanal is not water soluble, pure hexanal $(0.1 \mathrm{ml})$ was deposited inside the desiccator, adjacent to the water/salt solution. For the binary compounds exposures, the solutions were poured into separate beakers and placed in the desiccator $(20 \mathrm{ml}$ and $50 \mathrm{~g}$ of salt each). Control samples were produced by exposing paper to the water/salt mixture only. The volatile compounds used and the environmental conditions are listed in Tables 1 and 2.

Measurements of the volatile compounds in the headspace of the desiccators were carried out with Dräger and Gastec detector tubes. According to the suppliers, the relative standard deviations (RSD) on the quantitation are 5\%, except for formic acid (RSD 15-10\%) and formaldehyde (RSD 20-15\%). The measurement of hexanal had to be done with the tubes designed for acetaldehyde measurement as commercial hexanal-dedicated tubes were not available. The conversion for the concentration calculation was done as follows. At saturation, hexanal generates $2000 \mathrm{ppm}$ in the headspace, which yielded a measurement of $26 \mathrm{ppm}$ (equivalent) acetaldehyde. The level of hexanal was then calculated as $77(\sim 2000 / 26)$ times the level of acetaldehyde measured assuming a linear relationship.

Three air sampling measurements were made in each desiccator containing the paper samples: once the equilibrium was reached, a few days after the beginning of the exposure, and again at the end

Table 1

Exposure conditions of $\mathrm{W} 1$ in the temperature range $20.6-21.6^{\circ} \mathrm{C}$.

\begin{tabular}{|c|c|c|c|}
\hline Volatile compounds & $\begin{array}{l}\text { Solution's } \\
\text { concentration } \\
\text { (vol/vol \%) }\end{array}$ & $\begin{array}{l}\text { RH during } \\
\text { exposure (\%) }\end{array}$ & $\begin{array}{l}\text { Average } \\
\text { concentration } \\
\text { in air with } \\
\text { papers (ppm) }\end{array}$ \\
\hline Water (control) & 100 & 54 & \\
\hline Water (control) & 100 & 75 & \\
\hline Acetaldehyde (Ac) & 0.017 & 54 & $60 \pm 4$ \\
\hline Acetic acid (AA) & 2.17 & 54 & $\begin{array}{l}\mathrm{AA}: 41 \pm 4 \\
\mathrm{NO}_{\mathrm{x}}: 0.5\end{array}$ \\
\hline Acetic acid & 2.17 & 54 & $\begin{array}{l}\mathrm{AA}: 37 \pm 4 \\
\mathrm{NO}_{\mathrm{x}}<0.5\end{array}$ \\
\hline Acetic acid & 2.17 & 75 & $67 \pm 9$ \\
\hline Acetic acid & 1.00 & 75 & $28 \pm 4$ \\
\hline Formaldehyde (F) & 1.98 & 54 & $30 \pm 5$ \\
\hline Formaldehyde & 1.98 & 75 & $19 \pm 5$ \\
\hline Formic acid (FA) & 3.04 & 75 & $38 \pm 9$ \\
\hline Furfural & 1.14 & 54 & $82 \pm 8$ \\
\hline Hexanal & $0.10 \mathrm{ml}^{\mathrm{a}}$ & 54 & $810 \pm 280^{b}$ \\
\hline Hydrogen peroxide $\left(\mathrm{H}_{2} \mathrm{O}_{2}\right)^{\mathrm{c}}$ & 30 & 75 & $\begin{array}{l}\mathrm{H}_{2} \mathrm{O}_{2}: 30 \\
F<1 \\
\text { FA: } 3^{\mathrm{d}}\end{array}$ \\
\hline Acetaldehyde + acetic acid & $\begin{array}{l}0.012 \\
4.30\end{array}$ & 54 & $\begin{array}{l}\text { Ac: } 91 \pm 8 \\
\text { AA: } 40 \pm 4 \\
\mathrm{NO}_{\mathrm{x}}: 3 \pm 1\end{array}$ \\
\hline Formaldehyde + formic acid & $\begin{array}{l}3.90 \\
3.77\end{array}$ & 75 & $57 \pm 6,28 \pm 5$ \\
\hline $\mathrm{H}_{2} \mathrm{O}_{2}+$ formaldehyde $^{\mathrm{c}}$ & $\begin{array}{l}30 \\
4.00\end{array}$ & 75 & $\begin{array}{l}\mathrm{H}_{2} \mathrm{O}_{2}<1, \\
\mathrm{~F}: 16, \\
\text { FA: } 41^{\mathrm{d}}\end{array}$ \\
\hline $\begin{array}{l}\mathrm{H}_{2} \mathrm{O}_{2}+\text { formaldehyde } \\
\text { without papers }^{\mathrm{c}}\end{array}$ & $\begin{array}{l}30 \\
4.00\end{array}$ & 100 & $\begin{array}{l}\mathrm{H}_{2} \mathrm{O}_{2}<1, \\
\mathrm{~F}: 31, \\
\text { FA: } 20\end{array}$ \\
\hline
\end{tabular}

\footnotetext{
a $0.1 \mathrm{ml}$ of hexanal $98 \%$ in separate beaker (not mixed with water-salt solution)

b Measured with acetaldehyde detection tube.

c Average vapour concentration based on integration of polynomial fit curve.
}

d Detection made with formic acid tubes. 
Table 2

Exposure conditions of $\mathrm{W} 40$ at $21.3 \pm 0.3^{\circ} \mathrm{C}$ and $75 \% \mathrm{RH}$.

\begin{tabular}{|c|c|c|}
\hline & $\begin{array}{l}\text { Solution's concentration } \\
\text { (vol/vol \%) }\end{array}$ & $\begin{array}{l}\text { Average } \\
\text { concentration in air } \\
\text { with papers (ppm) }\end{array}$ \\
\hline Water (control) & 100 & \\
\hline Acetic acid & 1.00 & $34 \pm 5$ \\
\hline Formaldehyde & 1.98 & $24 \pm 5$ \\
\hline Formic acid & 1.52 & $28 \pm 5$ \\
\hline Furfural & 1.14 & $131 \pm 28$ \\
\hline $\begin{array}{l}\text { Formaldehyde }+ \text { formic } \\
\text { acid }\end{array}$ & $4.00,3.04$ & $64 \pm 5,24 \pm 5$ \\
\hline
\end{tabular}

of the exposure period. The vapour concentrations were in the range 20-80 ppm depending on the volatile compound (Tables 1 and 2), and were found to be relatively constant over the whole exposure period, except for hydrogen peroxide as detailed in section 3.1. For simplicity in the presentation of the results, the average concentrations of hydrogen peroxide and of its reaction products over the exposure period were obtained using a curve fit program (Table Curve 2D, Systat Software Inc.), and subsequently used in the graphs as well as for designating the corresponding exposed samples.

\subsection{Paper samples}

The two papers used as models were pure cotton cellulose filter papers, Whatman No. 1 (W1) and Whatman No. 40 (W40). W1 is neutral (cold extract $\mathrm{pH}=6.51 \pm 0.02$ ), has an ash content of $0.06 \%$ and a basis weight of $88 \mathrm{~g} \mathrm{~m}^{-2}$. W40 is more acidic (cold extract $\mathrm{pH}=5.68 \pm 0.06$ ), with an ash content of $0.007 \%$ and a basis weight of $92 \mathrm{~g} \mathrm{~m}^{-2}$. While the cellulose of W1 is unoxidized, that of W40 was found to have a sizeable degree of oxidation, evidenced by a copper number of $1.61 \pm 0.09$. Considering the value of $D P_{n}$ (number average degree of polymerization), this corresponds approximately to a content in total carbonyl groups of $26 \mu \mathrm{mol} \mathrm{g}-1$ (henceforth abbreviated $\mathrm{CO}_{\text {tot }}$ ), which, excluding the cellulose's reducing end-groups, yields $15 \mu \mathrm{mol} \mathrm{g}^{-1}$ in carbonyl groups on cellulose (henceforth abbreviated $\mathrm{CO}$ ) (see section 2.5). These papers were chosen as models because of their simple composition. W1 has been widely used for this very reason in studies of cellulose degradation, including work by the authors, while W40 was deemed to better represent more oxidized and acidic paper.

Sets of 100 paper strips $\left(2.5 \times 12 \mathrm{~cm}^{2}\right)$ were hung vertically on stainless steel holders and placed in the desiccators with their lower edges about $5 \mathrm{~cm}$ above the surface of the salt solution as shown in Fig. 1. The exposures lasted 52 days during which the desiccators were kept in the dark. After exposure, the samples were left to off-gas for 10 days prior to any further action. Despite this ventilation period it was not possible to rule out the residual presence of volatile compounds still absorbed in the paper samples, thus more emphasis will be given in the discussion on the data obtained upon real time exposure and less on the data obtained upon ageing.

\subsection{Hygrothermal ageing}

After the exposure and the desorption period, the samples were hygrothermally aged at $100{ }^{\circ} \mathrm{C}$ for 5 and 10 days, in hermetically closed Lab-Line hybridization tubes $(35 \mathrm{~mm}$ internal diameter (ID) $\times 147 \mathrm{~mm}, 144 \mathrm{ml}$ ) according to ASTM standard D6819 02(2007). During the ageing, the humidity in the tube is supplied and buffered by the paper, and stabilizes between 50 and $60 \% \mathrm{RH}$

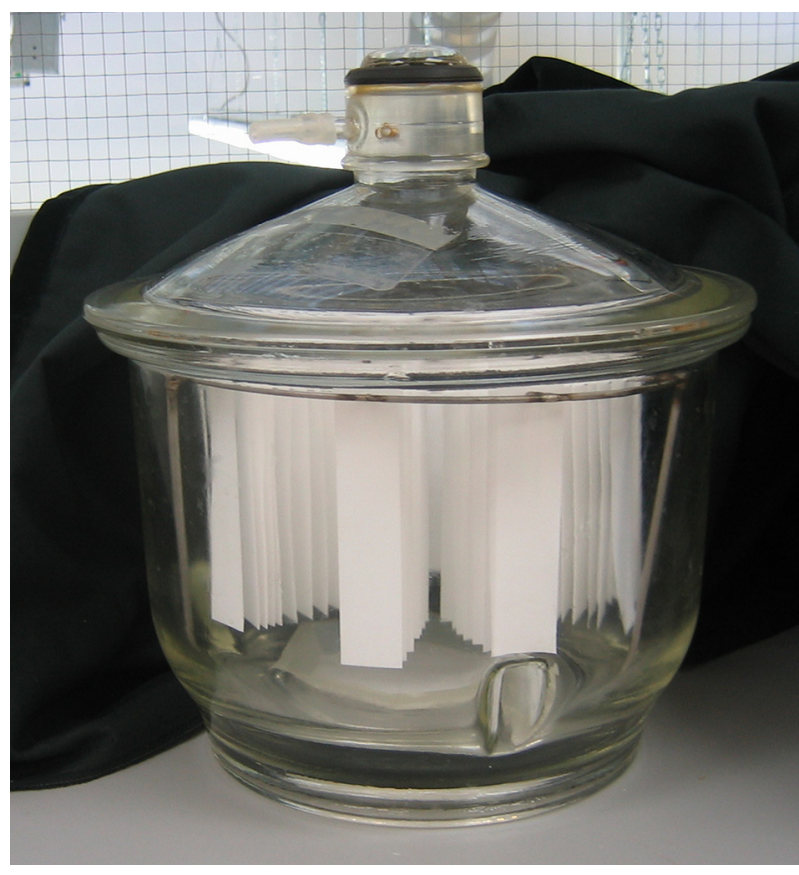

Fig. 1. Paper samples exposed to a volatile compound.

[36]. W40 samples were aged for 5 days only as degradation was deemed too pronounced after 10 days ageing.

\subsection{Physicochemical measurements}

Two methods were used for the determination of the degree of polymerization of cellulose $(D P)$ : viscometry $(\mathrm{V})$ and size-exclusion chromatography with multiangle light scattering and differential refractive index detection (SEC/MALS-DRI). Measurements were carried out in duplicate or triplicate.

SEC/MALS-DRI allows the experimental determination of the average molar masses of cellulose $\left(M_{\mathrm{n}}, M_{\mathrm{w}}, M_{\mathrm{z}}\right)$, and thus the corresponding $D P$ values $\left(D P_{\mathrm{n}}, D P_{\mathrm{w}}, D P_{\mathrm{z}}\right)$. The dissolution of the paper samples prior to analysis was carried out in $N, N$-dimethylacetamide (DMAc) with $8 \%$ lithium chloride according to a procedure detailed in a previous publication [37]. A 515 isocratic HPLC pump (Waters), ACC-3000T autosampler (Dionex), Dawn EOS MALS detector (Wyatt Technologies), and 2414 (Waters) differential refractive index (DRI) detector were part of the chromatographic set-up. The separation was carried out on a set of three Phenogel Linear(2) polystyrene divinyl benzene (PSDVB) columns (5- $\mu \mathrm{m}$ particlediameter mixed bed pores columns, Phenomenex) preceded by a Phenogel guard column $(5-\mu \mathrm{m}$, Phenomenex). The columns compartment and the MALS detector were thermostated at $60{ }^{\circ} \mathrm{C}$, the DRI was set to $55{ }^{\circ} \mathrm{C}$. The mobile phase was DMAc with $0.5 \%$ lithium chloride (wt/vol). The system was operated at a flow rate of $0.4 \mathrm{~mL} \mathrm{~min}^{-1}$ with an injection volume of $100 \mu \mathrm{L}$. The repeatability of the method was previously determined to be RSD\% $=2.5$ on $M_{\mathrm{W}}$ for 3 separate cellulose samples analysed two to three times nonconsecutively.

The average viscometric degree of polymerization of cellulose $\left(D P_{v}\right)$ was determined by measuring the intrinsic viscosity $([\eta])$ of a dilute cellulose solution in the solvent cupriethylenediamine (CED), according to the standard method ISO 5351. To minimize the alkaline degradation of oxidized cellulose in CED [38,39], all W40 samples underwent reduction in $0.01 \mathrm{M}$ ethanolic solution of sodium borohydride for $17 \mathrm{~h}$ before measuring the viscosity. The 
sample size varied from 15 to $50 \mathrm{mg}$. The repeatability of the measurement (within the laboratory) as indicated in TAPPI (Technical Association of the Pulp and Paper Industry) Test Method T 230 om-99 is $4 \%$.

For polymers in dilute solutions, the relation between $[\eta]$ and the molar mass is described by the empirical Mark-HouwinkSakurada equation:

$[\eta]=K^{\prime} M_{v}^{a}$

Where $K^{\prime}$ and $a$ are constants for a given polymer-solvent system, temperature and molar mass range. For cellulose in CED the relationship has been formulated as [40]:

$[\eta]=0.91\left[D P_{\mathrm{v}}\right]^{0.85}$

$M_{\mathrm{V}}$ always falls between $M_{\mathrm{n}}$ and $M_{\mathrm{w}}$ [41]. For pure cellulose paper, $a$ is often found close to unity, and $M_{\mathrm{V}}$ is usually reported in the literature to be closer to $M_{\mathrm{w}}$ than to $M_{\mathrm{n}}$. Based on the fairly good correlation obtained in the experimental values of $D P_{\mathrm{w}}$ and $D P_{\mathrm{v}}$ (less than $10 \%$ difference in $90 \%$ of the cases, and less than $5 \%$ difference in $60 \%$ of the cases), both values were used indiscriminately and henceforth named 'DP' for convenience.

The rate of glycosidic bond cleavage $(k)$ as a function of time $(t)$ was estimated using the model based on first order kinetics proposed by Ekamstam [42], which uses the value of $D P_{n}$ at any given time $\left(D P_{n t}\right)$ as expressed in the following relationship with respect to its initial value $D P_{n t_{0}}$ :

$\left(1 / D P_{n t}-1 / D P_{n t_{0}}\right)=k t$

The following expression was used to convert $D P_{\mathrm{v}}$ into $D P_{n}$ when needed:

$\left[D P_{\mathrm{v}}\right]=\left[D P_{n}\right] \times[(1+a) \Gamma(1+a)]^{1 / a}$

Where $a$ is the Mark-Houwink coefficient for the cellulose/CED system, and $\Gamma(1+a)$ is the gamma function of $a$ evaluated by reference to tabulated values [43].

The copper number $(\mathrm{NCu})\left(\mathrm{g} \mathrm{Cu}_{2} \mathrm{O}\right)$ was determined according to TAPPI Test Method T $430 \mathrm{~cm}-99$, where the mass of paper was reduced from $1 \mathrm{~g}$ to $300 \mathrm{mg}$. Two to three repeat measurements were performed for each sample type. The repeatability of the measurement was $10 \%$. NCu represents an index for functions on cellulose and other compounds in paper which possess reducing properties [44]. These are mostly carbonyl functions, and in pure cellulose they arise from the $\mathrm{C} 1$ end-groups and from carbonyl groups along the macromolecule on C2, C3 and C6. While the former are informative of cellulose chain cleavage, the latter indicate cellulose oxidation. It is thus necessary to distinguish between them in order to assess cellulose oxidation. This can be done by subtracting from the total carbonyl groups content $\left(\mathrm{CO}_{\text {tot }}\right)$ the portion that relates to reducing end-groups, which can be roughly calculated based on the $D P_{n}$ values, to yield the content in carbonyl functions on the cellulose (CO). In this study, in order to better estimate the oxidation of cellulose, the linear relationship between $\mathrm{CO}$ and NCu determined by Röhrling et al. [44] as $\mathrm{CO}=(\mathrm{NCu}-0.07) /$ $0.06\left(\mu \mathrm{mol} \mathrm{g}{ }^{-1}\right)$ was used .

The machine direction zero-span tensile strength of paper was measured according to TAPPI Test Method T231 cm-96 using a Troubleshooter Pulmac Instrument. Zero-span breaking length (BL) was calculated using the moisture-free basis weight of the paper samples. Twenty repeat measurements were carried out per sample type. The repeatability of the measurement was $5 \%$. Breaking Length was calculated as follows:
$\mathrm{BL}=102000(T / R)$

where $\mathrm{BL}=$ breaking length $(\mathrm{m}), T=$ tensile strength $\left(\mathrm{kN} \mathrm{m}^{-1}\right)$ $\left(1 \mathrm{kgf} / 15 \mathrm{~mm}=0.654 \mathrm{kN} \mathrm{m}^{-1}\right)$ and $R=$ basis weight (dry) $\left(\mathrm{g} \mathrm{m}^{-2}\right)$.

The cold extraction $\mathrm{pH}$ and the yellowness index measurement methodologies are described in section 1 in the supplementary material. Graphs in the supplementary material file are labelled S1 to S3.

\subsection{Migration of volatile compounds through paper stacks}

Three stacks of $13 \mathrm{~W} 1$ strips $\left(2.5 \times 12 \mathrm{~cm}^{2}\right)$ tightly wrapped in vapour barrier laminated aluminium foil (Marvelseal 360) with only one transversal side open were built as book mock ups. The paper strip stacks were exposed to different vapour concentrations of formic acid and acetic acid at $75 \% \mathrm{RH}$ for various periods in a $9 \mathrm{~L}$ desiccator. In this configuration, the migration of the volatile compounds into the stacks can occur only through the open section. One stack was removed weekly, and a strip from the middle was sampled for $\mathrm{pH}$ measurement. Tiny drops of universal $\mathrm{pH}$ indicator solution ( $\mathrm{pH}$ range $4-10$ ) were applied every $0.5 \mathrm{~cm}$ along the strip starting from the edge of the open side. The $\mathrm{pH}$ variation along the paper strip indicated the progressive migration of the acids. Further details of the experimental conditions can be found in Table 3. One 20-strip stack of W1 was exposed to $\mathrm{H}_{2} \mathrm{O}_{2}$ in a $9 \mathrm{~L}$ desiccator. The $\mathrm{H}_{2} \mathrm{O}_{2}$ migration was measured using a peroxide test strip test (Em Quant 10011-1, EMD Chemicals Inc.). The limit of quantitation (LOQ) reported by the manufacturer is $0.5 \mathrm{mg} \mathrm{L}^{-1}$.

\section{Results and discussion}

\subsection{Specific vapour phase environments}

The concentrations of volatile compounds in the desiccators are listed in Tables 1 and 2 . The vapour phase equilibrium with individual volatile compounds was reached in two days and was stable over the 52 days. With binary mixtures 5 days were necessary for full equilibration. No acid was detected after 52 days with the solutions of individual aldehydes, whether paper samples were present or absent in the desiccators. The oxidation of aldehydes to the corresponding acid did not seem to occur to any detectable level, which was attributed to the absence of an oxidant in the system. This confirms previous research where the oxidation of formaldehyde in the presence of lead and copper materials was not observed [45].

A side-reaction was found to occur between the carboxylic VOCs and magnesium nitrate used to regulate the $\mathrm{RH}$ to $54 \%$, producing nitrogen oxides. With formic acid, about $10 \mathrm{ppm}$ of $\mathrm{NO}_{\mathrm{x}}$ were

Table 3

Exposure conditions for the migration of volatile compounds through W1 stacked papers at $21.3 \pm 0.3{ }^{\circ} \mathrm{C}$ and $75 \% \mathrm{RH}$. The dimensions of the open edges were $0.2 \times 1.5 \mathrm{~mm}^{2}$ for the 13 strips stack and $0.3 \times 2.5 \mathrm{~mm}^{2}$ for the 20 strips stack.

\begin{tabular}{llll}
\hline & $\begin{array}{l}\text { Solution's } \\
\text { concentration } \\
\text { (vol/vol \%) }\end{array}$ & $\begin{array}{l}\text { Average concentration } \\
\text { in air with papers }(\mathrm{ppm})\end{array}$ & $\begin{array}{l}\text { Exposure period } \\
\text { (week) }\end{array}$ \\
\hline Acetic acid & 0.10 & 4 & $1,2,3$ \\
& 0.05 & 1 & 2,3 \\
Formic acid & 0.01 & $0.4^{\mathrm{a}}$ & 2,3 \\
& 0.15 & 2 & $1,2,3$ \\
$\mathrm{H}_{2} \mathrm{O}_{2}$ & 0.05 & 0.5 & 2,3 \\
\hline
\end{tabular}

${ }^{a}$ Estimated; not measured with detection tubes. 
generated. It was thus decided to carry out new formic acid exposures of the samples using sodium chloride (75\% RH) instead of magnesium nitrate. With acetic acid, the release of $\mathrm{NO}_{\mathrm{x}}$ was smaller, clearly measurable in one case ( $3 \mathrm{ppm})$, and suspected in trace amounts in two cases $(<0.5$ and $0.5(=\mathrm{LOQ}))$. The samples were still considered worth studying further even though the exposures were also repeated using $\mathrm{NaCl}$ salt as $\mathrm{RH}$ adjuster.

The monitoring of the concentrations of volatile compounds present in vapour phase in the desiccators containing hydrogen peroxide showed that chemical reactions took place during the exposure period. As shown in Fig. 2a, in the desiccator containing W1 in which a solution of $\mathrm{H}_{2} \mathrm{O}_{2}$ (30\%) was placed, the concentration of the latter rapidly increased reaching $36 \mathrm{ppm}$ in 15 days, but was followed by a slow decay over the remaining exposure period. Concomitantly, up to $7 \mathrm{ppm}$ of organic acids (measured with a detector tube calibrated for formic acid) were progressively formed. This was attributed to the gradual degradation and off-gassing of acids from the paper upon reaction with $\mathrm{H}_{2} \mathrm{O}_{2}$ (see section 3.2.1.1). When both $\mathrm{H}_{2} \mathrm{O}_{2}$ (30\%) and formaldehyde (4\%) were introduced in a desiccator with $W 1$, the concentration of $\mathrm{H}_{2} \mathrm{O}_{2}$ never raised above LOQ $(<1 \mathrm{ppm})$ during the whole exposure period, while a rapid production of organic acids occurred, most likely predominantly formic acid given the two chemical compounds present (Fig. 2b). The level of formaldehyde reached about 30 ppm in 7 days, but then declined quickly while the formic acid was gradually generated, reaching a plateau at about $47 \mathrm{ppm}$. To better understand the chemistry taking place and to characterize the reactivity of $\mathrm{H}_{2} \mathrm{O}_{2}$ with formaldehyde, an experiment was set up without the paper samples and at a relative humidity of $100 \%$, thus avoiding any possible interference of the $\mathrm{NaCl}$ salt solution. Fig. 2c shows that formic acid was produced, reaching a plateau around $35 \mathrm{ppm}$ at 35 days, while formaldehyde initially at $40 \mathrm{ppm}$ during a few days was steadily consumed after that. $\mathrm{H}_{2} \mathrm{O}_{2}$ did not attain a measurable concentration during the experiment period. This shows that the oxidation of formaldehyde to formic acid by $\mathrm{H}_{2} \mathrm{O}_{2}$ had occurred in the air. It also proves that the presence of $\mathrm{W} 1$ contributed to a faster and higher conversion yield of formaldehyde (Fig. $2 b$ and $c$ ), indicating that paper surface chemistry and/or degradation chemistry play a role.

The conversion of formaldehyde to formic acid in alkaline solutions was already known in the 19th century [46], and more recently, this conversion was speculated to occur in the presence of $\mathrm{H}_{2} \mathrm{O}_{2}$ at $100 \% \mathrm{RH}$ [47]. While it is known that this reaction can happen in an aqueous solution, it was not clear from the literature whether it occurred in high yield in the vapour phase or in porous materials such as cellulose.

\subsection{Exposure of paper strips to volatile compounds}

By exposing papers to various volatile compounds at ambient conditions of temperature and $\mathrm{RH}$, and by studying the various effects on papers and in real time, not only of individual volatile compounds, but also of their mixtures, the present research expands beyond past and recent studies based on individual VOCs exposures at high temperature [21,22]. Figs. 3-5 and S1-S3 (in the supplementary material) show the changes in the physicochemical properties of the papers exposed to volatile compounds and hygrothermally aged.

\subsubsection{Individual volatile compounds}

3.2.1.1. Exposure to formic acid and to hydrogen peroxide. Hydrogen peroxide in average concentration of $30 \mathrm{ppm}$ (mixed, as explained above, with an average of 3 ppm of organic acids) $\left({ }^{\prime} \mathrm{H}_{2} \mathrm{O}_{2}\right.$ $30+\mathrm{OA}^{\prime}$ ) and formic acid ( $38 \mathrm{ppm}$ ) ('FA 38') were found to be the most reactive volatile compounds toward cellulose, with considerable damage observed after the 52 day exposure, and resulting in a decrease in DP for W1 of $91 \%$ and 39\%, respectively (Fig. 4b). This

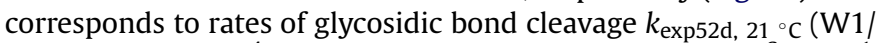

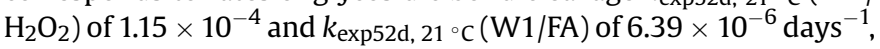

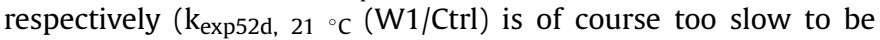
measured), and indicates also that cellulose degrades about 18 times faster when exposed to $\mathrm{H}_{2} \mathrm{O}_{2}$ than to formic acid at similar concentrations. The spectacular decrease in DP of W1 exposed to $\mathrm{H}_{2} \mathrm{O}_{2}$ (3163-293) was actually the largest possible as cellulose has reached the levelling-off degree of polymerization (LODP). As a result further change in DP upon ageing could hardly be measured [48]. Such a large degradation could explain the release by the paper of 3 ppm organic acids as measured [15,19].

The exposure to $\mathrm{H}_{2} \mathrm{O}_{2}$ also modified greatly the other measured properties of W1, with the exception of the yellowness index (YI), which decreased slightly initially (Fig. S3b), most likely due to the bleaching effect of $\mathrm{H}_{2} \mathrm{O}_{2}$. The oxidation of cellulose rose very significantly, with $\mathrm{NCu}=5.0$ (Fig. S1b), which amounts to approximately $83 \mu \mathrm{mol} \mathrm{g}^{-1} \mathrm{CO}_{\text {tot }}$, i.e. $42 \mu \mathrm{mol} \mathrm{g}^{-1} \mathrm{CO}$ (Fig. 3b). This high $\mathrm{CO}$ value lies in the upper limit of the oxidation range measured for a set of historic European rag papers from the 16th to the 19th century (5-45 $\mu \mathrm{mol} \mathrm{g}^{-1} \mathrm{CO}$ ) [49] and compares to the

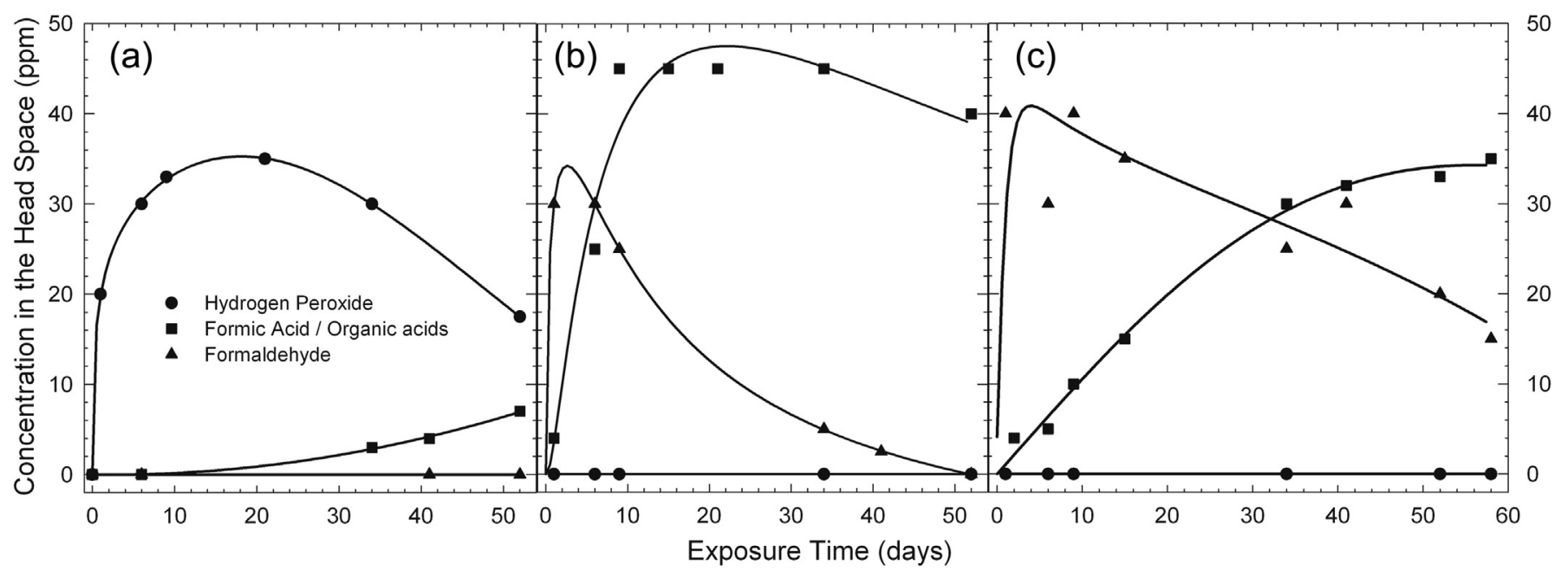

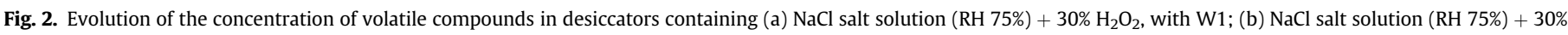
$\mathrm{H}_{2} \mathrm{O}_{2}+4 \%$ formaldehyde, with W1; (c) $30 \% \mathrm{H}_{2} \mathrm{O}_{2}+4 \%$ formaldehyde (RH $100 \%$ ) without W1. 


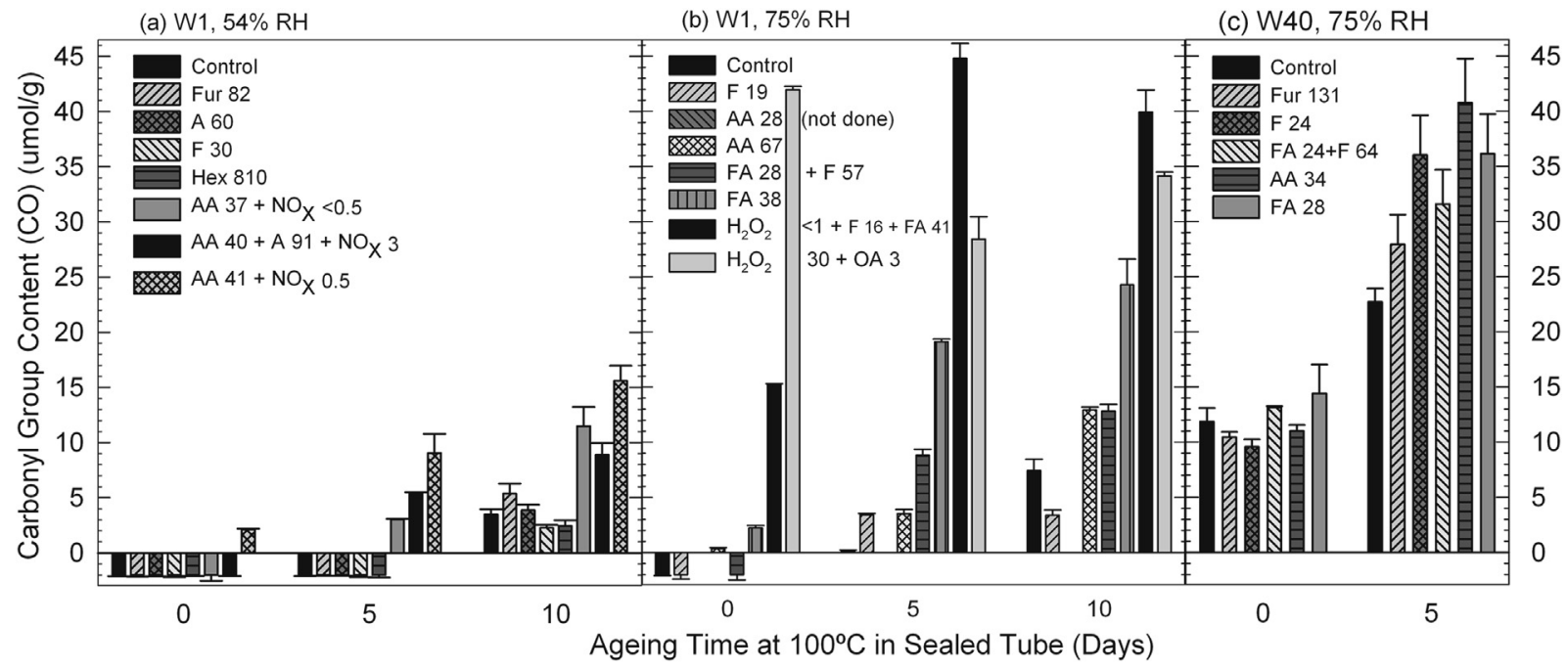

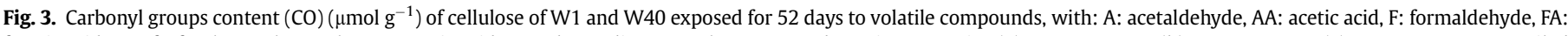

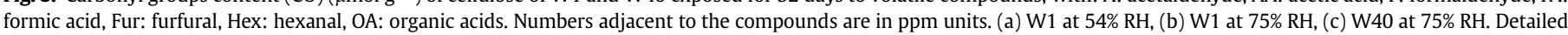
data can be found in Tables 1 and 2 . Zero values have been offset at -2 for better visualisation.

oxidation state of iron-gall ink corroded papers [50]. Thus, besides hydrolysis, significant oxidation of the cellulose hydroxyl groups took place (a rough back-calculation shows that to account exclusively for the reducing end-groups, NCu should be approximately of 2.5 in that case). The $\mathrm{BL}$ results were consistent with the other measurements, with a decrease of $63 \%$ upon exposure to $\mathrm{H}_{2} \mathrm{O}_{2}$. Hydrogen peroxide is known to be a non-selective oxidant to cellulose and induce oxidation of the $2-\mathrm{OH}, 3-\mathrm{OH}$ or $6-\mathrm{OH}$ to carbonyl or carboxyl groups in acidic conditions, as well as oxidative depolymerization, leading to loss of fibre strength [51]. The present results, in gas phase, are consistent with this action of $\mathrm{H}_{2} \mathrm{O}_{2}$. After 5 days of ageing, BL was as low as 1.0 (Fig. 5b) and after 10 days, the samples were too fragile to undergo the measurement. The yellowing increased significantly upon ageing as well. It is known that oxidative bleaches used for pulp and paper oxidize cellulose [5254] and lead to colour reversion of paper (browning) [55,56].

Conversely, the impact of the exposure to formic acid on the oxidation of $\mathrm{W} 1$ was more modest, with $\mathrm{NCu}=0.55$ (Fig. S1b), which corresponds to $8 \mu \mathrm{mol} \mathrm{g}{ }^{-1} \mathrm{CO}_{\text {tot, }}$, i.e. $2 \mu \mathrm{mol} \mathrm{g}^{-1} \mathrm{CO}$ (Fig. 3b). Indeed, an acid is expected to produce primarily acid catalyzed hydrolysis of cellulose. BL decreased slightly and the $\mathrm{pH}$ varied from 6.5 (W1 control) to 5.8 (Fig. S2b). Degradation increased considerably upon ageing. After 5 days, the drop in DP was $73 \%$ larger than for the aged W1 control, and after 10 days the LODP was reached (Fig. 4b). The rate of glycosidic bond cleavage upon ageing was about five times higher than for $\mathrm{W} 1$ control, with $\mathrm{k} t_{\text {ageing, }} 100{ }^{\circ} \mathrm{C}$ $(\mathrm{W} 1 / \mathrm{FA})=5.51 \times 10^{-4} \mathrm{days}^{-1}\left(\mathrm{k} t_{\text {ageing, }} 100{ }^{\circ} \mathrm{C}(\mathrm{W} 1 / \mathrm{Ctrl})\right.$ $=1.05 \times 10^{-4}$ days $^{-1}$ ). Oxidation also increased considerably with ageing, with $\mathrm{NCu}$ of 2.6 after 5 days, and 3.9 after 10 days, which correspond to 43 and $64 \mu \mathrm{mol} \mathrm{g}^{-1} \mathrm{CO}_{\text {tot, }}$ respectively, i.e. 19 and $24 \mu \mathrm{mol} \mathrm{g}{ }^{-1} \mathrm{CO}$, a 20 -fold increase. This shows that the hygrothermal ageing enhanced both hydrolysis and oxidation reactions initiated in cellulose during the VOC exposure. This degradation upon ageing was again corroborated by a decrease in $\mathrm{BL}, \mathrm{pH}$ and by a small increase of YI (Fig. 5b, S2b and S3b). Traces of formic acid still absorbed in the fibres after the sample desorption period could (a) $\mathrm{W} 1,54 \% \mathrm{RH}$

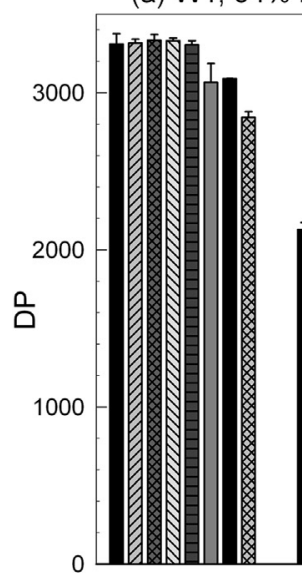

(b) $\mathrm{W} 1,75 \% \mathrm{RH}$

(c) $\mathrm{W} 40,75 \% \mathrm{RH}$

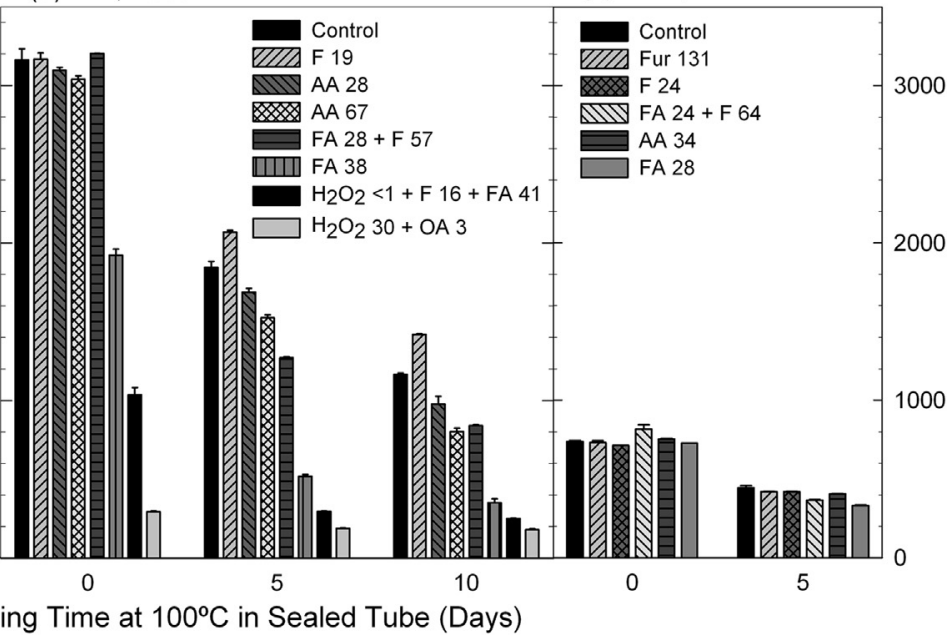

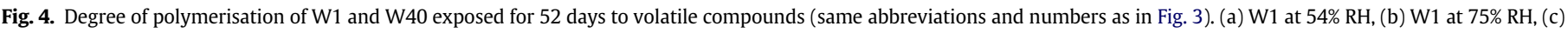
W40 at 75\% RH. Detailed data can be found in Tables 1 and 2 . 
(a) $\mathrm{W} 1,54 \% \mathrm{RH}$

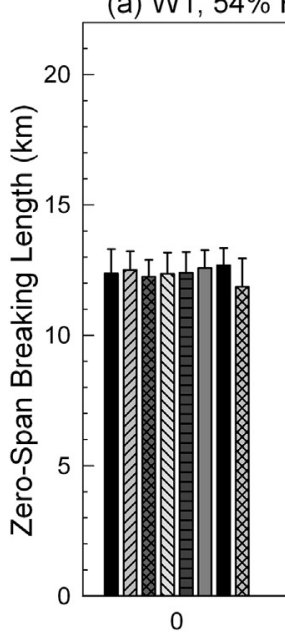

(b) $\mathrm{W} 1,75 \% \mathrm{RH}$

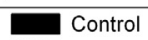

DII Fur 82

A 60

MIIV 30

Hex 810

$\square \mathrm{AA} 37+\mathrm{NO}_{\mathrm{x}}<0.5$

$\mathrm{AA} 40+\mathrm{A} 91+\mathrm{NO} \times 3$

$\mathrm{AA} 41+\mathrm{NO}_{\times} 0.5$
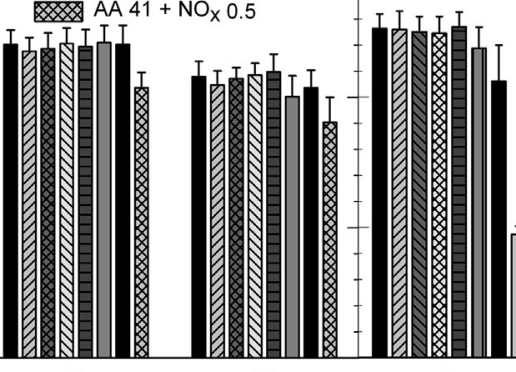

10

Ageing Time at $100^{\circ} \mathrm{C}$ (c) $\mathrm{W} 40,75 \% \mathrm{RH}$

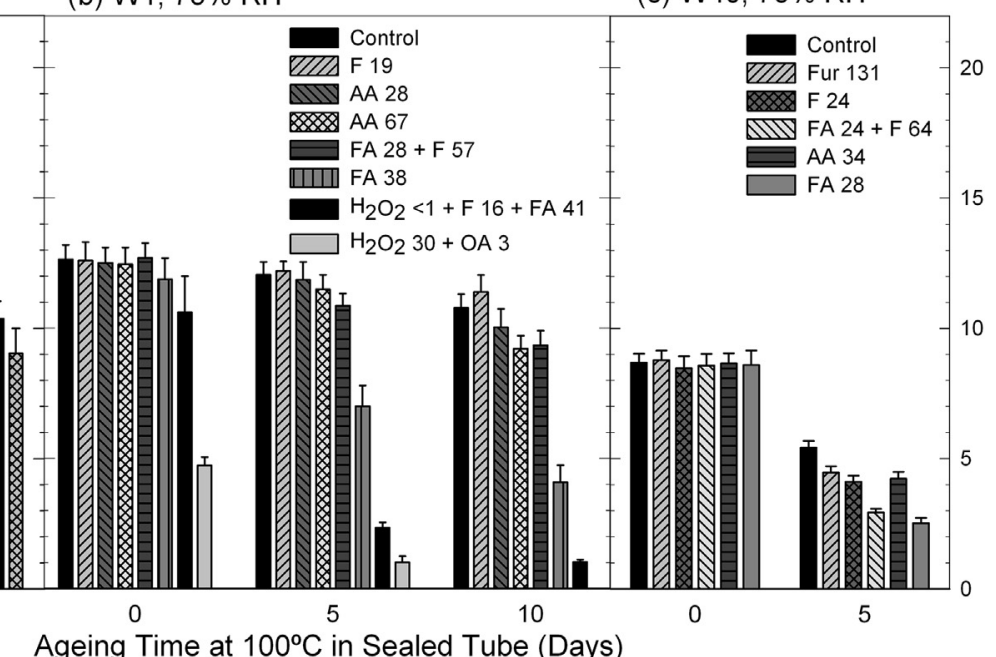

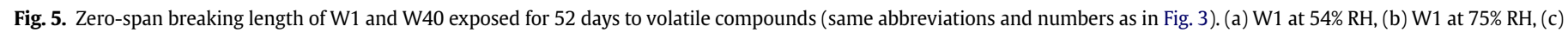
W40 at 75\% RH. Detailed data can be found in Tables 1 and 2.

be responsible for this fast ageing behaviour, but this could not be verified.

Upon the extensive deterioration observed for $\mathrm{W} 1$, exposures of W40 to $\mathrm{H}_{2} \mathrm{O}_{2}$ were not carried out. At the end of the exposure period to formic acid (28 ppm), only small changes in the physicochemical properties of W40 were measured (Figs. 3c-5c and S1c-S3c), indicating no immediate reaction of cellulose with formic acid. Nevertheless, upon ageing the oxidation increased more than for $\mathrm{W} 1$, with $\mathrm{NCu}=4.4$ after 5 days ageing (Fig. S1c), corresponding to $72 \mu \mathrm{mol} \mathrm{g}^{-1} \mathrm{CO}_{\text {tot }}$, i.e. $36 \mu \mathrm{mol} \mathrm{g}^{-1} \mathrm{CO}$ (Fig. 3c), and pointing to the higher sensitivity of W40 to oxidation upon ageing compared to W1. A difference of $25 \%$ in DP was observed compared to the aged W40 control sample (Fig. 4c). The rate of glycosidic bond cleavage $\mathrm{k} t_{\text {ageing, } 100{ }^{\circ} \mathrm{C}}(\mathrm{W} 40 / \mathrm{FA})$ was $6.33 \times 10^{-4}$ days $^{-1}$, which is only slightly higher than $k t_{\text {ageing, } 100{ }^{\circ} \mathrm{C}}(\mathrm{W} 1 / \mathrm{FA})$.

3.2.1.2. Exposure to acetic acid. Acetic acid exposures (28 ppm and $67 \mathrm{ppm}$ ) at 75\% RH caused little damage to W1 cellulose as shown by marginal drops of $2 \%$ and of $4 \%$ in DP, respectively (Fig. $4 \mathrm{~b}$ ). As observed with formic acid, the level of oxidation upon exposure to the highest acetic acid concentration (67 ppm) was negligible, with $\mathrm{NCu}=0.33$ (Fig. S1b), corresponding to $4 \mu \mathrm{mol} \mathrm{g}^{-1} \mathrm{CO}_{\text {tot, }}$, i.e. a CO content of $0.4 \mu \mathrm{mol} \mathrm{g}^{-1}$ (Fig. 3b). After hygrothermal ageing, some additional measurable adverse impact was found compared to the aged W1 control sample, especially at the highest concentration, with further reduction in DP of $17 \%$ after 5 days ( $28 \mathrm{ppm}$ exposure induced $8 \% \mathrm{DP}$ drop). Oxidation slightly increased, with $\mathrm{NCu}=0.75$ and 1.74 upon 5 and 10 days, respectively, which corresponds to 11 and $28 \mu \mathrm{mol} \mathrm{g}^{-1} \mathrm{CO}_{\text {tot }}$, i.e. 4 and $13 \mu \mathrm{mol} \mathrm{g}^{-1} \mathrm{CO}$. No significant immediate changes in $\mathrm{BL}$ and $\mathrm{pH}$ were observed, and after ageing their decrease was still moderate (Fig. 5b and S2b). The correlation between the evolution of DP and zero-span tensile strength of pure cellulose paper upon hygrothermal ageing has been shown to be non-linear [57] in conditions where acid catalyzed hydrolysis degradation is predominant. Whereas a small DP drop can easily be measured for cellulose with relatively high DP, mechanical properties are much less sensitive. Conversely, when the DP has substantially decreased and further DP change is hardly measurable, the variations in tensile strength allow evaluating further degradation.

In the experiments carried out at $54 \% \mathrm{RH}$ W1 samples exposed to acetic acid (37 ppm) underwent more degradation than during the exposures at 75\% RH, with a 7\% DP loss, and a pH drop from 6.6 to 6.3 (Fig. 4a and S2a). Here again, no oxidation occurred, with $\mathrm{NCu}=0.2$ (Fig. S1a), i.e. $2 \mu \mathrm{mol} \mathrm{g}^{-1} \mathrm{CO}_{\text {tot }}$ attributed to the reducing end-groups alone (Fig. 3a). After 5 and 10 days ageing, oxidation increased slightly more than for the respective aged control samples, with $\mathrm{NCu}=0.68,\left(10 \mu \mathrm{mol} \mathrm{g}^{-1} \mathrm{CO}_{\text {tot }}\right.$, i.e. $\left.3 \mu \mathrm{mol} \mathrm{g}^{-1} \mathrm{CO}\right)$ and $1.58\left(25 \mu \mathrm{mol} \mathrm{g}^{-1} \mathrm{CO}_{\mathrm{tot}}\right.$, i.e. $\left.11 \mu \mathrm{mol} \mathrm{g}^{-1} \mathrm{CO}\right)$, a level comparable to that obtained after ageing upon the exposures at $75 \% \mathrm{RH}$. The changes in DP and YI (Fig. S3a) were also somewhat more pronounced than for the respective aged control samples. As explained in section 3.1, it is likely that during this exposure, trace levels of $\mathrm{NO}_{\mathrm{x}}$, below the LOQ of $0.5 \mathrm{ppm}$, were formed (faint colour of the detection tube). Taking into account the results of the exposures to acetic acid at $75 \% \mathrm{RH}$, which had indicated a fairly low reactivity of the acid, it was assumed that this possible trace presence of $\mathrm{NO}_{\mathrm{x}}$ had contributed to some extent to the moderate changes observed upon the exposure at $54 \% \mathrm{RH}$. This is discussed further on (section 3.2.2.2).

Similarly, acetic acid exposure (34 ppm) did not cause immediate deterioration on W40 nor did it affect significantly its ageing behaviour, in terms of DP, NCu, CO and YI (Figs. 3c and 4c, S1c and S3c). Upon 5 days ageing the DP decreased slightly (by 9\%), similarly as for $\mathrm{W} 1$, whereas oxidation augmented more significantly to $\mathrm{NCu}=4.3$, corresponding to $70 \mu \mathrm{mol} \mathrm{g}^{-1} \mathrm{CO}_{\text {tot }}$, i.e. $41 \mu \mathrm{mol} \mathrm{g}^{-1} \mathrm{CO}$, a four-fold increase. The cellulose degradation was also reflected by a decrease in $\mathrm{pH}(5.2)$ and by a decrease in BL (22\%) (Fig. 5c and S2c).

Further investigation is needed to understand fully the considerably lower reactivity towards cellulose of acetic acid compared to that of formic acid. However, it can be observed that in the papers, which have a $\mathrm{pH}$ in the range $5.5-6.5$, acetic acid $(\mathrm{pKa}=4.75)$ is most likely in partially dissociated form. Formic acid being a stronger acid ( $\mathrm{pKa}=3.75$ ) is more dissociated, therefore resulting in a higher concentration of hydronium ions in the paper, which could explain its higher hydrolytic activity towards cellulose. These considerations are based on solution chemistry, but are to some extent also relevant to paper due to the residual water present in the fibres, which in $\mathrm{W} 1$ and $\mathrm{W} 40$ was measured in the range $5.4-5.8 \%(\mathrm{wt} / \mathrm{wt}$ ).

3.2.1.3. Exposures to aldehydes. Individual aldehydes (formaldehyde, acetaldehyde, hexanal and furfural) did not cause physicochemical degradation in any of the two papers immediately after 
exposure whether at $54 \% \mathrm{RH}$ or $75 \% \mathrm{RH}$. Moreover, it was observed that the exposures to formaldehyde even seemed beneficial. W1 exposed to formaldehyde ( $30 \mathrm{ppm}$ ) at $54 \% \mathrm{RH}$ showed slightly less yellowing than the control samples (Fig. S3a), and at $75 \% \mathrm{RH}$ (19 ppm) smaller decreases in DP, pH, BL and YI were recorded after ageing (Figs. 4b and 5b, S2b and S3b). After 10 days of ageing W1 exposed to formaldehyde at $75 \% \mathrm{RH}$ (19 ppm) maintained a higher DP (by 22\%) and a lower oxidation level than the control samples, with $\mathrm{NCu}=0.78$ (Fig. S1b), corresponding to $12 \mu \mathrm{mol} \mathrm{g}^{-1} \mathrm{CO}_{\text {tot }}$, i.e. about $3 \mu \mathrm{mol} \mathrm{g}^{-1} \mathrm{CO}$ (for W1 control $\mathrm{CO}=7 \mu \mathrm{mol} \mathrm{g}{ }^{-1}$ ) (Fig. 3b). The rate of glycosidic bond cleavage upon ageing was about $30 \%$ lower than for $\mathrm{W} 1$ control $\left(\mathrm{k} t_{\text {ageing, }} 100^{\circ} \mathrm{C}(\mathrm{W} 1 / \mathrm{F})=7.51 \times 10^{-5}\right.$ and $\mathrm{k} t_{\text {ageing, }}$ $100{ }^{\circ} \mathrm{C}(\mathrm{W} 1 / \mathrm{Ctrl})=1.05 \times 10^{-4}$ days $\left.^{-1}\right)$. This retention of the properties measured upon ageing was not observed with the samples exposed to acetaldehyde (Figs. $3 \mathrm{a}-5 \mathrm{a}$ and $\mathrm{S} 1 \mathrm{a}-\mathrm{S} 3 \mathrm{a}$ ).

After 5 days of ageing, the $\mathrm{NCu}$ of $\mathrm{W} 40$ exposed to furfural (131 ppm) and to formaldehyde (24 ppm) at 75\% RH increased slightly, from 3.1 (aged W40 control) to 3.45 and 3.94 (Fig. S1c), respectively, indicating that from $51 \mu \mathrm{mol} \mathrm{g}^{-1}, \mathrm{CO}_{\text {tot }}$ rose marginally to 56 and $65 \mu \mathrm{mol} \mathrm{g}^{-1}$, i.e. CO from $24 \mu \mathrm{mol} \mathrm{g}^{-1}$ (W40 control) to 28 and $36 \mu \mathrm{mol} \mathrm{g}^{-1}$ (Fig. 3c). The BL of W40 was also moderately affected upon ageing (Fig. 5c). The pH of W40 exposed to formaldehyde decreased slightly less (of $0.2 \mathrm{pH}$ units) upon ageing than for the control samples (Fig. S2c). It appears that carboxylic acids formed somewhat more slowly during the ageing for W40 exposed to formaldehyde. It is known that during the oxidation of cellulose by unspecific oxidants, aldehyde groups are first formed, and further oxidation results in the formation of carboxylic groups on cellulose and small carboxylic acids [51]. These results suggest that the formaldehyde slightly slowed down the course of cellulose oxidation of W40 as well, and corroborate the results obtained with W1.

One hypothesis for the counter-degradation effect of formaldehyde could be a preferential weak affinity bonding. Formaldehyde may be weakly bonded near reactive sites on the cellulose macromolecule (glycosidic bonds and hydroxyl groups), thereby limiting the access for acids, oxidants and/or water molecules, and lowering the rates of acid hydrolysis and oxidation. In the textile industry, formaldehyde is used as a cross-linking agent for cellulose, indicating its reactivity. The reaction occurs under specific conditions of water swelling of the fibres, acid catalyst, reactant concentration and temperature [58,59]. It has been shown to evolve through methylene ether cross-linking, where each methylene bridge blocks two hydroxyl groups from adjacent cellulose macromolecules (Cell-O- $\mathrm{CH}_{2}-\mathrm{O}-\mathrm{Cell}$ ) [60]. Whether such crosslinking can also occur in the present experimental conditions, and to what extent, is not known. The lack of degradation from formaldehyde exposure has been observed recently on other materials too, such as aged colour photographic prints [61] and soda silicate glass [62].

\subsubsection{Binary mixtures of volatile compounds}

3.2.2.1. Exposure to formaldehyde/formic acid. Corroborating the results obtained upon individual exposure to formaldehyde, less damage was found in both W1 and W40 when exposed to a mixture of formic acid (FA) and formaldehyde (F) than when exposed to formic acid alone (Figs. $3 \mathrm{~b}$ and $\mathrm{c}-5 \mathrm{~b}$ and $\mathrm{c}$ and $\mathrm{S} 1 \mathrm{~b}$ and $\mathrm{c}-\mathrm{S} 3 \mathrm{~b}$ and $\mathrm{c})$. The greatest reduction in damage was observed for W1 ('FA 28 + F 57'). While formic acid (38 ppm) had caused a DP loss of $39 \%$, no change in DP was measured upon exposure to the mixture of formic acid (28 ppm) and formaldehyde (57 ppm) (Fig. 4b). After 5 days of ageing, the DP loss was inferior by $59 \%$ compared to the sample exposed to formic acid alone, and the rate of glycosidic bond cleavage was over three times slower, with $\mathrm{k} t_{\text {ageing, } 100{ }^{\circ} \mathrm{C}}(\mathrm{W} 1 / \mathrm{FA}+\mathrm{F})=1.70 \times 10^{-4}$ days $^{-1}$. It has to be kept in mind that this is still about three times faster than for W1 Control.
Oxidation occurred on W1 but was also much reduced (by 50\%) compared to the oxidation incurred by the formic acid exposure: $\mathrm{NCu}$ increased slightly from 0.2 after the exposure to 1.2 and 1.7 upon 5 and 10 days ageing (Fig. S1b), corresponding to 2, 18 and $27 \mu \mathrm{mol} \mathrm{g}^{-1} \mathrm{CO}_{\mathrm{tot}}$, respectively, i.e. 0, 9 and $13 \mu \mathrm{mol} \mathrm{g}^{-1} \mathrm{CO}$ (Fig. 3b).

Similarly, W40 samples exposed to the binary mixture of formic acid (24 ppm) and formaldehyde (64 ppm) ('FA $24+$ F 64') showed $12 \%$ retention in DP and a significantly better BL compared to the samples exposed to formic acid alone (28 ppm) ('FA 28') (Figs. 4c and $5 \mathrm{c}$ ). Less oxidation was also measured (13vs $36 \mu \mathrm{mol} \mathrm{g}^{-1} \mathrm{CO}$ ) (Fig. 3c). After 5 days ageing, as observed earlier with W40, oxidation increased with $\mathrm{NCu}=3.9$, corresponding to $64 \mu \mathrm{mol} \mathrm{g}^{-1}$ $\mathrm{CO}_{\text {tot }}$, i.e. $32 \mu \mathrm{mol} \mathrm{g}{ }^{-1} \mathrm{CO}$, a similar degree of ageing-induced oxidation than that incurred when the paper was exposed to formaldehyde alone and somewhat less than upon exposure to formic acid alone.

More research is needed to fully understand these inhibiting effects but a competition of unreactive and more reactive molecules near the reactive cellulose functions can be proposed.

3.2.2.2. Exposure to acetic acid/NO $\mathrm{NO}_{x}$ and to acetaldehyde/acetic acid/ $N O_{x}$. As previously described, in one instance acetic acid (AA) (41 ppm) and magnesium nitrate were suspected of generating small amounts of $\mathrm{NO}_{\mathrm{x}}(0.5 \mathrm{ppm})$ (Table 1$)$. What was intended as an individual volatile compound exposure most likely became a binary exposure. In that case, the deterioration observed in W1 was a $14 \%$ drop in DP compared to the W1 control sample (Fig. 4a), and some marginal oxidation ( $\mathrm{NCu}=0,38$, i.e. $5 \mu \mathrm{mol} \mathrm{g}^{-1} \mathrm{CO}_{\text {tot }}$ and $2 \mu \mathrm{mol} \mathrm{g}^{-1}$ CO) (Fig. 3a and S1a). After 5 days of ageing, the DP difference was of $47 \%$ compared to the aged control sample, with $\mathrm{k} t_{\text {ageing, } 100{ }^{\circ} \mathrm{C}}(\mathrm{W} 1 /$ $\left.\mathrm{AA}+\mathrm{NO}_{\mathrm{x}} 0.5\right)=1.74 \times 10^{-4}$ days $^{-1}$, the degradation rate of W1 control kt $t_{\text {ageing, } 100{ }^{\circ} \mathrm{C}}(\mathrm{W} 1 / \mathrm{Ctrl})$ being $1.05 \times 10^{-4}$ days $^{-1}$. As reported earlier in section 3.2.1.2, since acetic acid alone ( 28 and $67 \mathrm{ppm}$ at $75 \%$ $\mathrm{RH}$ ) had been found to cause minor damage, it was concluded that $\mathrm{NO}_{\mathrm{x}}$ contributed sizeably to this degradation. This is also consistent with the hypothesis of the presence of trace $\mathrm{NO}_{\mathrm{x}}$ (sub-LOQ) in one case of exposure to acetic acid at 54\% $\mathrm{RH}$ that was assumed to accelerate the degradation. Chain cleavage of cellulose due to acetic acid vapours was reported earlier by the authors [20], and could possibly have been partially due to the production of $\mathrm{NO}_{\mathrm{x}}$ in low concentration, which, being an unexpected side-reaction, was not measured at the time. Indeed, the harmful effects of $\mathrm{NO}_{\mathrm{x}}$ on papers have been previously reported by various authors [21,63-65].

Likewise, upon the same side-reaction with the magnesium nitrate salt, up to $3 \mathrm{ppm}$ of $\mathrm{NO}_{\mathrm{x}}$ were produced in the mixture of acetaldehyde (A) (91 ppm) with acetic acid (AA) (40 ppm) (Table 1). Here, the intended binary volatile compound exposure had become a tertiary exposure ('AA $+\mathrm{A}+\mathrm{NO}_{\mathrm{x}} 3^{\prime}$ ). Remarkably, even though $\mathrm{NO}_{\mathrm{x}}$ was in higher concentration in this tertiary exposure, the DP of W1 decreased less than for the exposure where acetaldehyde was absent but where the occurrence of $\mathrm{NO}_{\mathrm{x}}$ was smaller (' $\mathrm{AA}+\mathrm{NO}_{\mathrm{x}}$ $0.5^{\prime}$ ) (Fig. 4a). With $\mathrm{NCu}=0.05$, i.e. $\mathrm{CO}=0 \mu \mathrm{mol} \mathrm{g}^{-1}$ (Fig. 3a and $\mathrm{S} 1 \mathrm{a})$, the oxidation was also much lower for the exposure 'AA $+\mathrm{A}+\mathrm{NO}_{\mathrm{x}} 3^{\prime}$ than for the exposure without acetaldehyde. Other properties including $\mathrm{BL}, \mathrm{pH}$, and YI followed the same tendency (Fig. 5a, S2a and S3a). Similar to the observations with the mixture of formic acid with formaldehyde, the presence of acetaldehyde led to a considerable inhibition of the reactivity of acetic acid and acetic acid/ $\mathrm{NO}_{\mathrm{x}}$ on $\mathrm{W} 1$. This trend was maintained after ageing. In terms of the degradation rate, $k t_{\text {ageing, } 100{ }^{\circ} \mathrm{C}}\left(\mathrm{W} 1 / \mathrm{AA}+\mathrm{A}+\mathrm{NO}_{\mathrm{x}} 3\right)$ was $1.23 \times 10^{-4}$ days $^{-1}$, i.e. slightly slower than $\mathrm{k} t_{\mathrm{ageing}}, 100{ }^{\circ} \mathrm{C}(\mathrm{W} 1 /$ $\mathrm{AA}+\mathrm{NO}_{\mathrm{x}}$ 0.5).

3.2.2.3. Exposure to formaldehyde/formic acid/hydrogen peroxide. Fig. 4b shows that despite a larger degradation compared to the W1 
control (DP 67\% lower), the DP of W1 exposed to the mixture initially intended, prepared with formaldehyde (4\%) and $\mathrm{H}_{2} \mathrm{O}_{2}$ (30\%), was still 3.5 times higher than that of the samples exposed to $\mathrm{H}_{2} \mathrm{O}_{2}$ alone (30\%). From $83 \mu \mathrm{mol} \mathrm{g}{ }^{-1} \mathrm{CO}_{\text {tot }}$ due to the exposure to $\mathrm{H}_{2} \mathrm{O}_{2}$ (i.e. $42 \mu \mathrm{mol} \mathrm{g}^{-1} \mathrm{CO}$ ), in the presence of formaldehyde, the value of $\mathrm{NCu}$ dropped to 1.7 (Fig. S1b), with $\mathrm{CO}_{\text {tot }}$ of $27 \mu \mathrm{mol} \mathrm{g}^{-1}$, i.e. $15 \mu \mathrm{mol} \mathrm{g}^{-1} \mathrm{CO}$, indicating $64 \%$ less oxidation (Fig. $3 \mathrm{~b}$ ). This shows that when formaldehyde was present, considerably less cellulose chain cleavage and oxidation occurred. As explained in section 3.1, it has to be reminded here that $\mathrm{H}_{2} \mathrm{O}_{2}$ was found to be highly reactive in the gas phase, leading to the production of formic acid when formaldehyde was present, and leaving less than $1 \mathrm{ppm}_{2} \mathrm{O}_{2}$ in the air (Fig. 2b). The actual volatile compounds to which the samples were exposed in the two cases thus were $\mathrm{H}_{2} \mathrm{O}_{2}(<1 \mathrm{ppm}) /$ formaldehyde (16 ppm)/formic acid (41 ppm) $\left({ }^{\prime} \mathrm{H}_{2} \mathrm{O}_{2}<1+\mathrm{F}\right.$ $16+$ FA 41') and $\mathrm{H}_{2} \mathrm{O}_{2}$ (30 ppm)/organic acids (3 ppm) $\left({ }^{\prime} \mathrm{H}_{2} \mathrm{O}_{2}\right.$ $30+\mathrm{OA}^{\prime}$ ), respectively. Under similar formic acid concentrations, W1 exposed to the mixture hydrogen peroxide/formaldehyde/formic acid suffered $46 \%$ less DP loss than W1 exposed to formic acid alone. Despite its very low concentration, $\mathrm{H}_{2} \mathrm{O}_{2}$ appears therefore extremely aggressive towards cellulose, as already observed (section 3.2.1.1). The lower degradation when formaldehyde was mixed with $\mathrm{H}_{2} \mathrm{O}_{2}$ compared to the dramatic effect of $\mathrm{H}_{2} \mathrm{O}_{2}$ alone was also observed consistently in the values of BL of W1 (Fig. 5b). This damage dampening result was however completely annulled after ageing, as shown by the oxidation taking place after 5 and 10 days, respectively, indicating 85 and $88 \mu \mathrm{mol} \mathrm{g}^{-1} \mathrm{CO}_{\text {tot, }}$ i.e. 45 and $40 \mu \mathrm{mol} \mathrm{g}^{-1} \mathrm{CO}$, for the sample exposed to ' $\mathrm{H}_{2} \mathrm{O}_{2}<1+\mathrm{F} 16+\mathrm{FA} 41^{\text {' }}$ ( $\mathrm{NCu}$ of 5.2 and 5.3). Surprisingly, it was even higher than for the sample exposed to ' $\mathrm{H}_{2} \mathrm{O}_{2} 30+\mathrm{OA} 3^{\prime}$ ' $(\mathrm{NCu}$ of 5.6 and 6.1 after 5 and 10 days, i.e. 92 and $100 \mu \mathrm{mol} \mathrm{g}^{-1} \mathrm{CO}_{\text {tot }}$, respectively, and 28 and $\left.35 \mu \mathrm{mol} \mathrm{g}{ }^{-1} \mathrm{CO}\right)$. It has to be noted though, that at the near-LODP values such as those obtained for ' $\mathrm{H}_{2} \mathrm{O}_{2} 30+\mathrm{OA} 3^{\prime}$, the measurements bear a higher imprecision.

Antagonistic effects upon mixing gases of different reactivity toward cellulose have been observed by other researchers. For instance, nitrogen dioxide $\left(\mathrm{NO}_{2}\right)$ is more reactive on paper than sulphur dioxide $\left(\mathrm{SO}_{2}\right)$. Adelstein reported that the damage observed on papers exposed to a mixture of $\mathrm{NO}_{2}$ and $\mathrm{SO}_{2}$ was smaller than when exposed to $\mathrm{NO}_{2}$ alone [66]. The mechanism of this is unclear. This aspect of the antagonism on the impact of VOCs needs further investigation.

\subsection{Migration of volatile compounds through paper stacks}

It is known that damage in books often starts at the edges, and deeper migration occurs with time [67-73]. Literature data is available on the migration of $\mathrm{SO}_{2}$ through stacks of papers or books [74]. The effect of paper additives such as rosin [75], metals and pigments [76,77] and calcium carbonate [77] on the migration or sorption of $\mathrm{SO}_{2}$ has also been studied. However, the migration rate of carboxylic acids, peroxides and nitrogen oxides remains unknown.

The migration of formic and acetic acids through a tight stack of W1 sheets at 75\% RH as a function of the dose of acid (ppb year) is presented in Fig. 6. It was expected that the most reactive compounds would be mainly adsorbed or retained at the edges of the paper stack while the non-reactive compounds would migrate deeper into the stack. However, the opposite situation was observed. Formic acid was found to migrate deeper into the paper stack than acetic acid and $\mathrm{H}_{2} \mathrm{O}_{2}$. The results show that, at a dose of 200 ppb year, formic acid would migrate deeper (about $4 \mathrm{~cm}$ ) than acetic acid by almost of factor of two.

The migration rate in $\mathrm{W} 1$ of pollutants in low concentration such as the levels found in archive repositories and archival boxes

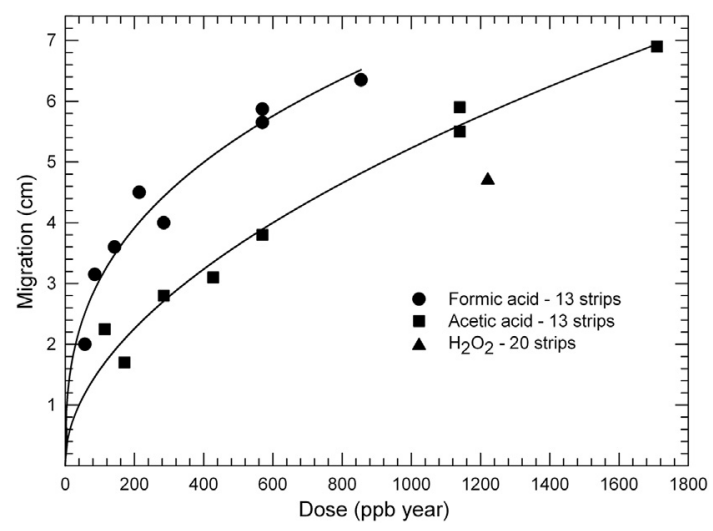

Fig. 6. Migration distance of volatile compounds through W1 stacks kept at $75 \% \mathrm{RH}$.

can be extrapolated using a dose-effect approach. Assuming that a concentration as high as $100 \mathrm{ppb}$ formic acid can be present in an enclosure [78], our data indicates that the time required to observe $4 \mathrm{~cm}$-deep migration would be about 2 years (200 ppb year/ $100 \mathrm{ppb}$ ) (Fig. 6). At a few ppb levels, formic acid would migrate less deep inside the paper, consequently leading to a larger degradation of cellulose at the edges than inside the stack, which is the situation often observed in old books. On the other hand, on-going natural acid hydrolysis and oxidation of cellulose inside the stacks also would generate formic acid, acetic acid and other low molar mass organic acids [15], which in turn would slowly migrate their way through the stack, towards the centre or the edges. Several factors could account for these observations, one being, as observed earlier, that at the $\mathrm{pH}$ of the paper, the equilibrium of formic acid should be more favourable to dissociation than that of acetic acid, leading to a higher concentration of hydronium ions. This larger amount of $\mathrm{H}_{3} \mathrm{O}^{+}$may explain the deeper migration of formic acid in the stack. Other factors that could possibly influence the migration are the size of the molecules and their physicochemical affinity with cellulose functional groups. Further investigation is thus needed to fully understand the kinetics and the equilibria at play in a stack of paper exposed to volatile compounds. Moreover, the results cannot be easily compared with previous research since data on the migration of pollutants in stacks in a specific environment is scarce. One exception is the work by Smith on old books dated from 1899 to 1964 [70]. A small increase in acidity was observed in the centre of the pages of the books which, based on our calculations, corresponded to an exposure to a dose of $\mathrm{NO}_{2}$ of about $1700 \mathrm{ppb}$ year with an average concentration of $18 \mathrm{ppb}$ of $\mathrm{SO}_{2}$. This brings the migration rate of $\mathrm{NO}_{2}$ and $\mathrm{SO}_{2}$ to the same order of magnitude as that observed with acetic and formic acids in the stacks.

\section{Conclusions}

The results of this research provided a better understanding of the relative reactivity of volatile compounds on paper at ambient temperature and $\mathrm{RH}$. Formic acid was by far the most destructive carboxyl functionalized VOC toward cellulose. Acetic acid was found to be mildly aggressive, although the results have to be put into perspective as a 52 days-exposure period is certainly short compared to real situations in archives which can sometimes approach several centuries. Additionally, when present in low concentrations, nitrogen oxides seemed to contribute sizeably to the degradation induced by the carboxylic VOCs, and the adverse effect of hydrogen peroxide was found to outreach largely the impact of formic acid. Furthermore, as shown by the exposures of the mock up books to volatile compounds, formic acid penetrates 
deeper inside stacks of papers than acetic acid and even $\mathrm{H}_{2} \mathrm{O}_{2}$, which shows its degradation potential in archives and libraries.

The aldehydes in individual exposures (acetaldehyde, hexanal, formaldehyde and furfural) did not affect non-oxidized cellulose but slightly affected pre-oxidized cellulose. It is noteworthy that the exposure to formaldehyde was actually found to lower the degradation rate of W1 upon ageing. However, since residual volatile compounds in the paper fibres after the post-exposure desorption period of the samples may have contributed to some extent to the effects observed, the results of the hygrothermally aged samples can be taken as indicative.

These degradation effects were found to be largely dampened during the multiple exposures, where the presence of the aldehydes - formaldehyde and acetaldehyde - resulted in a significant reduction of the degradation incurred by the reactive compounds cited above. In the case of the mix of formaldehyde with hydrogen peroxide, formic acid was produced thereby inducing a damage caused by the latter instead of the even larger damage that would be incurred by hydrogen peroxide.

Apart from $\mathrm{NO}_{\mathrm{x}}$, which is an exogenous pollutant, most of these compounds are endogenous as they are commonly released by papers upon natural ageing. The same effects as observed in this study are thus expected to occur through cross-contamination between neighbouring papers, such as in archival boxes. The results clearly show that ambient air quality mostly adversely affects the long-term preservation of historic papers. However, as real situations are extremely complex, more research is needed to better understand the degradation inhibitory effects observed in volatile compounds mixtures, especially those involving an acid or a strong oxidant with an aldehyde, chiefly formaldehyde, as well as the influence of other components than the cellulose in the paper, such as lignin, hemicelluloses, fillers and sizing material.

\section{Acknowledgements}

The authors are very grateful to Season Tse, Jane Sirois and Valérie Dupont for scientific discussions, helpful advices and comments during the writing and the editing of this paper.

\section{Appendix A. Supplementary data}

Supplementary data related to this article can be found at http:// dx.doi.org/10.1016/j.polymdegradstab.2013.05.017.

\section{References}

[1] Martin G, Blade N. Cultural property environment monitoring. In: Roy A, Smith P, editors. Preventive conservation practice, theory and research 1994. p. 159-63.

[2] Tétreault J. Airborne pollutants in museums, galleries and archives: risk assessment, control strategies and preservation management. Ottawa: Canadian Conservation Institute; 2003.

[3] Nguyen T-P. Indoor air pollution in the new building's storage areas of the French National Library: effects on the corrosion of copper and silver and on the paper cellulose - I. First results. In: 7th indoor air quality 2006 meeting. [Full text accessed from], <http://iaq.dk/iap/iaq2006/Nguyen_IAQ2006.pdf > ; 2006.

[4] Nguyen T-P, Dubus M, Saheb M, Mareynat S. Étude de la qualité de l'air dans les magasins de la Bibliothèque nationale de France: premiers résultats. In: Support/Tracé 2006;vol. 6. p. 48-57.

[5] Ryhl-Svendsen M, Clausen G. The effect of ventilation, filtration and passive sorption on indoor air quality in museum storage rooms. Stud Conserv 2009;54:35-48.

[6] Fenech A, Strlič M, Kralj Cigić I, Levart A, Gibson LT, de Bruin G, et al. Volatile aldehydes in libraries and archives. Atmos Environ 2010;44:2067-73.

[7] Ziegleder G. Volatile and odorous compounds in unprinted paperboard. Packag Technol Sci 1998;11:231-9.

[8] Havermans JBGA, de Feber MAPC, Genuit WJL, van Velzen GJ. Emission of volatile organic compounds from paper objects affected with iron-gall ink corrosion. In: Preprints of the ICOM committee for conservation 12th triennial meeting 1999;vol. 2. p. 513-6.

[9] Pedersoli Júnior JL, Ligterink FJ, van Bommel M. Non-destructive determination of acetic acid and furfural in books by solid-phase micro-extraction (SPME) and gas chromatography-mass spectrometry (GC/MS). Restaurator 2011;32:110-34.

[10] Doering T, Fischer P, Banik G, Binder U, Liers J. An approach to evaluate the condition of paper by a non-destructive analytical method. Adv Print Sci Technol 2001;27:27-39.

[11] Shahani CJ, Harrison G. Spontaneous formation of acids in the natural aging of paper. In: Daniels V, Donnithorne A, Smith P, editors. Works of art on paper books, documents and photographs: techniques and conservation. Baltimore Congress, 2-6 September 2002; London UK 2002. p. 189-92.

[12] Lattuati-Derieux A, Bonnassies-Termes S, Lavédrine B. Characterisation of compounds emitted during natural and artificial ageing of a book. Use of headspace-solid-phase microextraction/gas chromatography/mass spectrometry. J Cult Herit 2006;7:123-33.

[13] Strlič M, Kralj Cigić I, Kolar J, de Bruin G, Steemers T. The PaperVOC project: measurement and simulation of VOC emissions from paper. In: Past - present - prediction: about simulation techniques, dosimeters, sensors, in conservation research and application, COST strategic workshop 2007. Ohrid, FYR of Macedonia.

14] Strlič M, Kralj Cigić I, Kolar J, de Bruin G, Pihlar B. Non-destructive evaluation of historical paper based on $\mathrm{pH}$ estimation from VOC emissions. Sensors 2007; 7:3136-45.

15] Dupont A-L, Egasse C, Morin A, Vasseur F. Comprehensive characterisation of cellulose and lignocellulose degradation products in aged papers: capillary zone electrophoresis of low-molar mass organic acids, carbohydrates, and aromatic lignin derivatives. Carbohydr Polym 2007;68:1-16.

[16] Gaspar EM, Santana JC, Lopes JF, Diniz MB. Volatile organic compounds in paper - an approach for identification of markers in aged books. Anal Bioanal Chem 2010;397:369-80.

[17] Clark AJ, Calvillo JL, Roosa MS, Green DB, Ganske JA. Degradation product emission from historic and modern books by headspace SPME/GC-MS: evaluation of lipid oxidation and cellulose hydrolysis. Anal Bioanal Chem 2011;399:3589-600.

[18] Jablonský M, Katuščák S, Holúbková S, Hroboňová K, Lehotay J. The effect of acetic and formic acid formation during accelerated ageing on embrittlement of newsprint paper. Restaurator 2011;32:318-47.

[19] Ramahlo O, Dupont A-L, Egasse C, Lattuati-Derieux A. Emission rates of volatile organic compounds from paper. e-Preserv Sci 2009;6:53-9.

[20] Dupont A-L, Tétreault J. Study of cellulose degradation in acetic acid environments. Stud Conserv 2000;45:201-10.

[21] Menart E, De Bruin G, Strlič M. Dose-response function for historic paper. Polym Degrad Stab 2011;96:2029-39.

[22] Strlič M, Kralj Cigić I, Možir A, de Bruin G, Kolar J, Cassar M. The effect of volatile organic compounds and hypoxia on paper degradation. Polym Degrad Stab 2011;96:608-15.

[23] Kočar D, Strlič M, Kolar J, Pihlar B. A new method for determination of hydroperoxides in cellulose. Anal Bioanal Chem 2002;374:1218-22.

[24] Souguir Z, Dupont A-L, de la Rie ER. Formation of brown lines in paper: characterization of cellulose degradation at the wet-dry interface. Biomacromolecules 2008;9:2546-52.

[25] Jeong MJ, Dupont A-L, de la Rie ER. Degradation of cellulose at the wet-dry interface. I. study of the depolymerisation. Cellulose 2012;19(4):1135-47.

[26] Feldman LH. Discoloration of black and white photographic prints. J Appl Photogr Eng 1981;7:1-9.

27] Adelstein PZ, Reilly JM, Cupriks KM. Protection of microform image against oxidation. In: Environnement et Conservation de l'Écrit, de l'Image et du Son: Actes des Deuxièmes Journées Internationales d'études de l'ARSAG 1994 p. 31-8.

[28] Strlič M, Menart E, Kralj Cigić I, Kolar J, de Bruin G, Cassar M. Emission of reactive oxygen species during degradation of iron gall ink. Polym Degrad Stab 2010;95:66-71.

29] Strlič M, Kralj Cigić I, Možir A, Thickett D, de Bruin G, Kolar J, et al. Test for compatibility with organic heritage materials - a proposed procedure. ePreserv Sci 2010;7:78-86.

[30] Carter H, Bégin P, Grattan D. Migration of volatile compounds through stacked sheets of paper during accelerated ageing. Restaurator 2000:21:187-203.

[31] Bülow A, Bégin P, Carter H, Burns T. Migration of volatile compounds through stacked sheets of paper during accelerated ageing, Part I: variable temperature studies. Restaurator 2000;21(4):187-203.

[32] Dimitroff MA, Lacksonen JW. The diffusion of sulfur dioxide in air through stacked layers of paper. J Am Inst Conserv 1986;25:31-7.

[33] Guttman CM, Jewett KL. Protection of archival materials from pollutants: diffusion of sulfur dioxide through boxboard. J Am Inst Conserv 1993;32:81-92.

[34] Greenspan L. Humidity fixed points of binary saturated aqueous solutions J Res Bur Stand Sect A: Phys Chem 1977;81A:89-96.

[35] Tétreault J, Sirois J, Stamatopoulou E. Study of lead corrosion in acetic acid environment. Stud Conserv 1998;43:17-32.

[36] Sawoszczuk T, Barańki A, Łagan JM, Łojewski T, Zięba K. On the use of ASTM closed vessel tests in accelerated ageing research. J Cult Herit 2008;9:401-11.

[37] Dupont A-L. Cellulose in lithium chloride/N, N-dimethylacetamide, optimisation of a dissolution method using paper substrates and stability of the solutions. Polymer 2003;44(15):4117-26. 
[38] Lee SB, Feller RL, Bogaard J. Relation of cellulose chain scission to hot-alkalisoluble content during thermal and photochemical degradation of paper. J Imaging Sci 1985;29(2):61-4.

[39] Strlič M, Kolar J, Žigon M, Pihlar B. Evaluation of size-exclusion chromatography and viscometry for the determination of molecular masses of oxidised cellulose. J Chromatogr A 1998;805:93-9.

[40] Evans R, Wallis AFA. Cellulose molecular weights determined by viscometry. J Appl Polym Sci 1989;37:2331-40.

[41] Ross-Murphy SB. Nevell TP, Zeronian SH, editors. Cellulose chemistry and its application, chapter 8: properties and uses of cellulose solutions. New York: J Wiley; 1985. p. 202-22.

[42] Ekamstam A. Ueber das Verhalten der Cellulose in Mineralsäure-lösungen. I. Mitteil: Die bestimmung des molekulargewichts in phosphorsäure-lössung. Ber Dtsch Chem Ges A 1936;69:553-9.

[43] Davis PJ. Abramowitz M, Stegun IA, editors. Handbook of mathematical functions, gamma function and related function. Washington, DC: Nationa Bureau of Standards; 1972. p. 253-94.

[44] Röhrling J, Potthast A, Rosenau T, Lange T, Borgards A, Sixta H, et al. A nove method for the determination of carbonyl groups in cellulosics by fluorescence labeling. 2. Validation and applications. Biomacromolecules 2002;3: 969-75.

[45] Tétreault J, Cano E, van Bommel M, Scott D, Dennis M, Barthés-Labrousse M-G et al. Corrosion of copper and lead by formaldehyde, formic and acetic acid vapours. Stud Conserv 2003;48:237-50.

[46] Smith HM. Note on the estimation of formic aldehyde. The Analyst 1896;21: $148-51$.

[47] Raychaudhuri MR, Brimblecombe P. Formaldehyde oxidation and lead corrosion. Stud Conserv 2000;45:226-32.

[48] Krässig HA. Huglin MB, editor. Cellulose structure, accessibility and reactivity. Polymer monographs. Chapter 5: effect of structure and morphology on accessibility and reactivity, vol. 11. Singapore: Gordon and Breach Sci. Pub; 1993. p. 191.

[49] Henniges U, Schwanninger M, Potthast A. Non-destructive determination of cellulose functional groups and molecular weight in pulp hand sheets and historic papers by NIR-PLS-R. Carbohydr Polym 2009;76:374-80.

[50] Henniges U, Reibke R, Banik G, Huhsmann E, Hähner U, Prohaska T, et al. Iron gall ink-induced corrosion of cellulose: aging, degradation and stabilization. Part 2: application on historic sample material. Cellulose 2008;15:861-70.

[51] Lai Y-Z. Chemical degradation. In: Hon N-S, Shiraishi N, editors. Wood and cellulosic chemistry. 2nd ed. New York: Marcel Dekker Inc; 2001. p. 443-512.

[52] Lewin M, Epstein JA. Functional groups and degradation of cotton oxidized by hypochlorite. J Polym Sci 1962;58:1023-37.

[53] Potthast A, Rosenau T, Kosma P. Adv Polym Sci. In: Klemm D, editor. Polysaccharides II. Analysis of oxidized functionalities in cellulose, 205. Berlin Heidelberg: Springer-Verlag; 2006. p. 1-48.

[54] Burgess HD, Hanlan JF. Degradation of cellulose in conservation bleaching treatments. J Int Inst Conserv - Canadian Group 1980;4(2):15-21.

[55] Rapson HW, Spinner IH. Singh RP, editor. Brightness reversion in bleached pulps, the bleaching of pulp. Atlanta: TAPPI Press; 1979. p. 357-91.

[56] Burgess HD. The colour reversion of paper after bleaching. In: Petherbridge G, editor. Conservation of library and archival materials and the graphic arts. London Butterworth; 1987. p. 57-70.

[57] Zou X, Gurnagul N, Uesaka T, Bouchard J. Accelerated aging of papers of pure cellulose: mechanism of cellulose degradation and paper embrittlement Polym Degrad Stab 1994;43:393-402.
[58] Datye KV, Nabar GM. Studies in the reaction of formaldehyde with cellulose. Text Res J 1960;30:72-3.

[59] Balkar Singh CLJ, Pande A, Chipalkatti VB, Parikh RS. Studies of formaldehydecrosslinked cellulose: significance of swelling at the time of cross-linking. Text Res J 1970;40:940-7.

[60] Araki M. Chemical reaction between cellulose and formaldehyde I. Preparation of methylene cellulose and its methylation. Wood Res 1964;33:1-7.

[61] Fenech A, Strilič M, Degano I, Cassar M. Stability of chromogenic colour prints in polluted indoor environments. Polym Degrad Stab 2010;95:2481-5.

[62] Robinet L, Hall C, Eremin K, Fearn S, Tate J. Alteration of soda silicate glasses by organic pollutants in museums. J Non-Cryst Solids 2009;355:1479-88.

[63] Wan JKS, Depew MC. Effects of $\mathrm{NO}_{\mathrm{x}}$ exposure on paper: the role of free radicals. J Pulp Pap Sci 1996;22:j174-7.

[64] Reilly JM, Zinn E, Adelstein P. Atmospheric pollutant aging test method development. Final report to American Society for Testing and Materials. Rochester: Image Permanence Institute; 2001. p. 52-97.

[65] Jerosch $H$, Lavédrine $B$, Cherton J-C. The use of size exclusion chromatography (SEC) for the evaluation of paper degradation caused by nitrogen oxides in comparison with other methods. In: Works of art on paper, books, documents and photographs: techniques and conservation. Contributions to the Baltimore Congress 2002. p. 108-13.

[66] Adelstein PZ, Zinn ED, Reilly JM. Effect of atmospheric pollution on paper stability. J Pulp Pap Sci 2003;29:21-8.

[67] Jarrell TD, Hankins JM, Veitch FP. Deterioration of book and record papers. USDA Technical Bulletin no. 541. Washington D.C: United States Department of Agriculture, U.S. Government Printing Office; 1936.

[68] Lyth Hudson F. Acidity of 17th and 18th century books in two libraries. Pap Technol 1967;8(3):189-96.

[69] Smith RD. Paper impermanence as a consequence of pH and storage conditions. Libr Q 1969;39:153-95.

[70] Smith RD. A comparison of paper in identical copies of books from the Lawrence University, the Newberry, and the New York Public Libraries. Restaurator 1972;(2 Suppl.):1-76.

[71] Barrett TD. Early European papers, contemporary conservation papers: a report on research undertaken from fall 1984 through fall 1987. J Inst Pap Conserv 1989;13:3-107.

[72] Hindhaugh N. A pH survey of an acidic text block. Pap Conserv 1990;14:17-22.

[73] Havermans JBGA, Porck HJ. Capderou C, Monod S, editors. Natural aging of paper: characterization of differences between identical copies of books stored in the New York Public Library and the National Library of the Netherlands. La conservation à l'ère du numérique; 2002. p. 173-9.

[74] Gurnagul N, Zou X. The effect of atmospheric pollutants on paper permanence: a literature review. TAPPI J 1994;77(7):199-204.

[75] Edward CJ, Lyth Hudson F, Hockey JA. Sorption of sulphur dioxide by paper. J Appl Chem 1968;18:146-8.

[76] Atherton JB, Lyth Hudson F, Hockey JA. The effect of temperature, light and some transitional metal ions on sorption of sulphur dioxide by paper. J Appl Chem Biotechnol 1973;23:407-14.

[77] Lyth Hudson F, Milner WD. The permanence of paper: the use of radioactive sulphur to study the pick-up of sulphur dioxide by paper. Pap Technol 1961;2(2):155-61.

[78] Kontozova-Deutsch V, Deutsch F, Bencs L, krata A, Van Grienken R, De Wael k. Optimization of the ion chromatographic quantification of airborne fluoride, acetate and formate in the Metropolitan Museum of Art, New York. Talanta 2011;86C:372-6. 